\title{
Amputation rate of diabetic foot ulcer and associated factors in diabetes mellitus patients admitted to Nekemte referral hospital, western Ethiopia: prospective observational study
}

\author{
Firomsa Bekele $^{1^{*}}$ (I) and Legese Chelkeba ${ }^{2}$
}

\begin{abstract}
Background: Diabetes foot ulcer is a devastating and much-feared complication of diabetes. Diabetes foot ulcerations which developed gangrene can take weeks or months to heal and can sometimes not heal at all so that amputation for non-traumatic causes is a frequent outcome in the diabetic foot. Despite this, there is no finding on predictors of the amputation rate of diabetes foot ulcers in Ethiopia. Hence this study was aimed to identify factors associated with the amputation rate of diabetes foot ulcer patients in Nekemte referral hospital.

Patients and methods: A prospective observational study was conducted among adult diabetes foot ulcer patients admitted to Nekemte referral hospital from March 15 to June 15, 2018. A pus swab was obtained from the ulcers before any ulcer cleaning to conduct gram staining. The primary outcome was the amputation rate. Cox regression analysis was used to estimate the hazard ratios and time from study entry to healing was evaluated as censored event times by Kaplan-Meier curves.

Result: Over the study period, 115 diabetes foot ulcer patients were admitted to the NRH; of these patients, 64(55.65\%) were males while the mean age of participants was $44.4 \pm 14.7$. A total of 34(29.57\%) of the diabetes foot ulcer were overweight and 16(13.91\%) were obese while the mean \pm standard deviation of body mass index (BMI) was $24.94 \pm 3.69 \mathrm{~kg} / \mathrm{m} 2$ and a total of $56(48.69 \%)$ diabetic foot ulcer had a diabetic complication.

Of patients with diabetic foot ulcer, 35(30.43\%) were undergone lower extremity amputations (LEA). Patients who were prescribed with inappropriate antibiotics were unlikely to heal. A total of $18(46.15 \%)$ of the patients who were taken inappropriate antibiotics were healed whereas 21(53.85\%) were not healed $(P=0.017)$. Besides, the higher the Wagner grade, the worse the outcome of healing. A total of $19(21.84 \%)$ and $16(57.14 \%)$ of patients with grade $<4$ and grade $\geq 4$, respectively, did not heal $(P=0.005)$.
\end{abstract}

(Continued on next page)

\footnotetext{
* Correspondence: firomsabekele21@gmail.com

'Department of Pharmacy, College of Health Science, Mettu University, Mettu, Ethiopia

Full list of author information is available at the end of the article
}

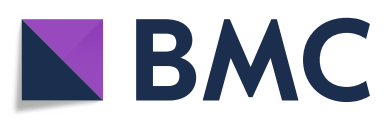

(- The Author(s). 2020 Open Access This article is licensed under a Creative Commons Attribution 4.0 International License, which permits use, sharing, adaptation, distribution and reproduction in any medium or format, as long as you give appropriate credit to the original author(s) and the source, provide a link to the Creative Commons licence, and indicate if changes were made. The images or other third party material in this article are included in the article's Creative Commons licence, unless indicated otherwise in a credit line to the material. If material is not included in the article's Creative Commons licence and your intended use is not permitted by statutory regulation or exceeds the permitted use, you will need to obtain permission directly from the copyright holder. To view a copy of this licence, visit http://creativecommons.org/licenses/by/4.0/ The Creative Commons Public Domain Dedication waiver (http://creativecommons.org/publicdomain/zero/1.0/) applies to the data made available in this article, unless otherwise stated in a credit line to the data. 
(Continued from previous page)

Conclusion: The amputation rate of diabetes foot ulcers was rapid for patients prescribed inappropriate antibiotics and higher grades of the foot ulcer. Therefore, the presence of clinical pharmacists plays a pivotal role to promote the appropriate use of antibiotics and besides the daily care, special attention should be given for patients having an advanced grade of diabetes foot ulcer.

Keywords: Diabetes foot ulcer, Diabetes mellitus, Amputation rate, Associated factors, Nekemte referral hospital

\section{Background}

Diabetes mellitus is a chronic disease that needs longterm medical attention to prevent the development of its complications [1]. The development of diabetes foot ulcers increases a patient's risk of mortality [2].

Different treatment protocols which include applying vascular intervention, anti-infection treatment, surgical operation, and postoperative wound care have been performed to increase the healing rate of the diabetes foot ulcer. Despite these, the reported diabetic foot ulcer healing rates from multiple series were poor [3].

Amputation of the lower extremities is the commonly occurred outcome for the DFU [4]. Approximately, more than half were progressed to infections that may result in amputations, disability, prolonged hospitalization, and death [5]. Due to prolonged healing time, many patients will need to be hospitalized for treatment [6]. For people with diabetes who have an active ulcer, the final healing rates are $65-75 \%$ for those attending a hospital, while around $15-20 \%$ of all people with an ulcer undergo amputation, depending on the duration of follow-up [7].

The size of the ulcer was greater in the amputation group compared to healed ulcers which can predict diabetes foot ulcer healing [8]. Despite this, the feet of diabetes patients were ignored by health care providers which could have an economic impact on the patient and health care system as a result of long-term in-hospital treatment and/or amputation $[1,9]$.

Determinants of ulcer healing in diabetes patients are generally essential in establishing management strategy in addition to their routine application as predictors of the outcome. Therefore, they are useful in the early identification of diabetes patients with high risk for foot ulcers to decrease the risk of amputation [10].

Diabetes mellitus patients whose ulcer progressed to Chronic do not show the well-defined sequence of ulcer healing. An increase in wound size and surface may empirically be determinants of poor healing [2]. In Ethiopia, patient behavior of poor diabetes foot ulcer treatment practice, and the absence of good quality service of diabetes foot ulcer may have led to foot infections which result in limb amputation. Only a few pharmacists were assigned to avoid the inappropriate use of antibiotics in the Nekemte referral hospital by intervening problems at only dispensing levels. Despite this, no study has been conducted on the amputation rate of diabetic foot ulcers in NRH. Therefore, this study was tried to determine the factor that affect the amputation rate of diabetes foot ulcer patients.

\section{Methods \\ Study design, period and area}

A prospective observational study was conducted at NRH from March 15 to June 15, 2018 to assess the amputation rate of diabetes foot ulcers. The hospital is found in Nekemte town, which is located $330 \mathrm{~km}$ to the west of Addis Ababa, the capital city of Ethiopia. The hospital is a referral hospital and gives health services for more than 10 million people living in western Ethiopia. There were about 2420 diabetic patients who have been following the diabetic clinics annually.

\section{Study participants and eligibility criteria}

Patients $\geq 18$ years who were admitted to the hospital due to no- traumatic chronic diabetes foot ulcer with visible foot lesions were included.

\section{Study variables and outcomes}

The primary outcome was the amputation rate. Independent variables included were sex, age, residence, educational level, marital status, type of diabetes mellitus, antibiotic given, previous history of ulcer, grade of diabetes foot ulcer, and presence of co-morbidity. The Wagner classification of diabetes foot ulcers was used to assess the grades of foot ulcers. The magnitude of foot ulcer was determined by multiplying the largest by the second largest diameter perpendicular to the first [11]. The etiology of diabetes foot infection was identified by using gram stains. Amputation and healing status was measured using a checklist and assessed by close followed of the patient through a telephone interview of the patient/ caregiver/ proxy on a weekly basis. The ulcer of different sites which includes, dorsal/inter-digital toes, plantar fore foot/ 
mid foot/hind foot, plantar toes, dorsal foot, and heel were recorded to identify the location of diabetes foot ulcer.

\section{Sample size and sampling technique}

Single population proportion formula was used to calculate the required sample size by considering the incidence of amputation which is 29\% [12]. Accordingly, a sample of 316 was obtained. The expected number of source population in the study period, based on the average number of patients coming to the hospital was 156 . Finally, by using correction formula a total of 115 patients were included. Conveniently all patients during the study period full filling the eligibility criteria and willing to respond were included in the final analysis.

\section{Data collection process and management}

Data was collected using data abstraction format which was developed after reviewing different literature and adopting [5, 7-12]. One medical doctor, one nurse and one pharmacist were selected as data collectors. One medical doctor working in a medical ward who had not been involved in data collection was assigned to supervise the collected data. A pus swab was obtained from the ulcers before any ulcer cleaning and avoiding other contamination. The samples were delivered to the laboratory immediately and a thin smear was prepared on grease or oil free slides. Appropriateness of antibiotics was identified based on infectious diseases society of America (IDSA) standard guidelines for diagnosis and treatment of diabetes foot infection [13], which is based on the most likely coverage of antibiotics for treatments of diabetic foot infection for identified gram stain results and their correct dosage regimens. Five percent of the sample was pre-tested to check the acceptability and consistency of the data collection tool 2 weeks before the actual data collection.

\section{Data processing and analysis}

The data was entered into the computer using EPImanager 4.0.2 and analysis was done using statistical package for social sciences (SPSS) 24. Descriptive data was explained by frequency and percentage. The obtained results were explained by means and standard deviations (SD). Cox regression analysis was used to estimate the hazard ratios and Time from study entry to time to healing was evaluated as censored event times by Kaplan-Meier curves. The variables with a $p$-value of less than 0.05 had a statistically significant association with the healing of diabetic foot ulcers.

\section{Operational definitions}

\begin{abstract}
Chronic diabetes foot ulcer: Is defined as a foot ulcer unable to heal after 4 weeks [14].

Healed: The complete closure of the diabetes foot ulcer with normal skin and without, drainage or sinus formation.

Amputation: Removal of lower extremity limb which includes both

below ankle (minor) and below knee (major).

Appropriate antibiotics: Antibiotics prescribed per the infectious diseases society of America (IDSA) guideline for the diagnosis and treatment of diabetic foot infection recommendation based on gram stains and dosage regimens.

Inappropriate antibiotics: Antibiotics prescribed inconsistent with the infectious diseases society of America (IDSA) guideline for the diagnosis and treatment of diabetes foot infection recommendation based on gram stains and dosage regimens.

Grades of diabetes foot ulcer: For the purpose of this study we used the Wagner system for classification of diabetic foot ulcer which uses 6 wound grades (scored 0 to 5) to assess ulcer depth [15].

- Grade 0 diabetes foot ulcer: No ulcer, but the foot is at risk for

ulceration

- Grade 1 diabetes foot ulcer: Superficial ulceration

- Grade 2 diabetes foot ulcer: Ulcer with deep infection, but without involvement of the bone

- Grade 3 diabetes foot ulcer: Ulcer with osteomyelitis.

- Grade 4 diabetes foot ulcer: Presence of localized gangrene on the foot.

- Grade 5 diabetes foot ulcer: Presence of gangrene of the whole foot.
\end{abstract}

\section{Result}

Socio-demographic and clinical characteristics

During the study period, 115 diabetes foot ulcer patients were admitted to the NRH; of these patients, 64(55.65\%) were males. A total of 26(22.61\%) of them were in the age range of 58-67, and 56(48.69\%) of them had hypertension as comorbidity (Table 1). A total of $34(29.57 \%)$ of the diabetes foot ulcer were overweight and $16(13.91 \%)$ were obese while the mean body mass index (BMI) was $24.94 \pm 3.69 \mathrm{~kg} / \mathrm{m}^{2}$. From the sites of ulcers involved, a total of $67(58.26 \%)$ of them were developed over plantar toes/foot whereas, $31(26.96 \%)$ of ulcers were located on dorsal/interdigital toes, $9(7.83 \%)$ of the diabetes foot ulcers were located in the dorsal foot and $8(6.96 \%)$ of the ulcers were developed over heel [16]. The mean fasting blood glucose level among diabetic patients with foot ulcers was $147.93 \pm 45.03 \mathrm{mg}$ / $\mathrm{dl}$ and a total of 56(48.69\%) diabetes foot ulcers had a diabetes complication.

\section{Healing time of diabetes foot ulcer and associated factors} Over the study period, a total $35(30.43 \%)$ patients were undergone lower extremity amputations (LEA) and 80(69.57\%) were healed. Regarding the rate of wound healing (in $\mathrm{cm}^{2} /$ week): a total of $20(17.39 \%$ ) were healed $<1 \mathrm{~cm}^{2} /$ week, 22(19.13\%) were $1-2 \mathrm{~cm}^{2} /$ week and 38 (33.04\%) were $>2 \mathrm{~cm}^{2} /$ week whereas, the overall mean time to healing was $42 \pm 5.592$ days.

From the total diabetes foot ulcer patients, a total of $77(67 \%)$ of ulcers were progressed to infection and 
Table 1 Demographic and clinical patient characteristics of diabetes foot ulcer patients in Nekemte referral hospital, west Ethiopia, 2018

\begin{tabular}{|c|c|c|c|}
\hline Variables & & Frequency (n) & Percent (\%) \\
\hline \multirow[t]{2}{*}{ Gender } & Male & 64 & 55.65 \\
\hline & Female & 51 & 44.35 \\
\hline \multirow[t]{6}{*}{ Age (years) } & $18-27$ & 16 & 13.91 \\
\hline & $28-37$ & 14 & 12.17 \\
\hline & $38-47$ & 15 & 13.04 \\
\hline & $48-57$ & 24 & 20.87 \\
\hline & $58-67$ & 26 & 22.61 \\
\hline & $68-77$ & 20 & 17.39 \\
\hline \multirow[t]{2}{*}{ Types of DM } & Type 1 & 54 & 46.96 \\
\hline & Type 2 & 61 & 53.04 \\
\hline \multirow[t]{2}{*}{ Residence } & Urban & 58 & 50.43 \\
\hline & Rural & 57 & 49.57 \\
\hline \multirow[t]{4}{*}{ Educational level } & Illiterate & 24 & 20.87 \\
\hline & Primary school & 29 & 25.22 \\
\hline & Secondary school & 22 & 19.13 \\
\hline & Above Secondary school & 40 & 34.78 \\
\hline \multirow[t]{4}{*}{ Marital status } & Married & 80 & 69.57 \\
\hline & Single & 21 & 18.26 \\
\hline & Widow & 8 & 6.96 \\
\hline & Divorced & 6 & 5.22 \\
\hline \multirow[t]{4}{*}{ Types of co-morbidity } & Hypertension & 56 & 48.69 \\
\hline & Dyslipidemia & 40 & 34.78 \\
\hline & Coronary heart disease/ischemic heart disease & 41 & 35.65 \\
\hline & Peripheral vascular disease & 42 & 36.65 \\
\hline \multirow[t]{2}{*}{ Wagner's grade } & Grade $<4$ & 83 & 72.17 \\
\hline & Grade $\geq 4$ & 32 & 27.83 \\
\hline \multirow[t]{2}{*}{ Antibiotics given } & Appropriate & 38 & 49.35 \\
\hline & Inappropriate & 39 & 50.65 \\
\hline
\end{tabular}

$38(33 \%)$ of them did not. From the patients who developed an infection, gram- positive organisms were identified in $42(54.55 \%)$, gram-negative were identified in $20(25.97 \%)$ and polymicrobial were seen in 15(19.48\%) [16].

From the total patient's given antibiotics, a total of $38(49.35 \%)$ of them were prescribed appropriately and $39(50.65 \%)$ were prescribed inappropriately whereas, 38 $(49.35 \%)$ of the diabetic foot ulcer patients were never given antibiotics. Individual antibiotics prescribed includes; cloxacillin 56 (34.15\%), metronidazole 43 (26.22\%), ceftriaxone 33 (20.12\%), ampicillin 9(5.49\%), chloramphenicol 8(4.88\%), gentamycin 5 (3.05\%), ceftazidime $4(2.44 \%)$, ciprofloxacin 3 (1.83\%), vancomycin 2 (1.22\%), and amoxicillin $1(0.61 \%)$.

Neither age nor gender had an association with the outcomes of foot ulcers whereas; advanced grade of ulcer and inappropriate antibiotics use had an association with the healing of diabetes foot ulcers. Patients prescribed with inappropriate antibiotics were 2 times more likely to be amputated as compared to the patients given appropriate antibiotics $(\mathrm{AHR}=2.14$; 95\%CI:1.64,10.63). The higher grades of foot ulcers, the worse the outcome of healing. Diabetes foot ulcer patients presented with grade $\geq 4$ were 1.6 times more likely to be amputated as compared to the patients having grade $<4(\mathrm{AHR}=1.59 ; 95 \%$ CI:1.49,7.48) (Table 2).

The Kaplan-Meier survival analyses of the patients who were given appropriate and inappropriate antibiotics showed that the healing time of diabetes foot ulcer patients who were given inappropriate antibiotics were prolonged than diabetes foot ulcer patients who were given appropriate antibiotics (Fig. 1). 
Table 2 Predictors of amputation rate of diabetes foot ulcer and associated factors in Nekemte referral hospital, west Ethiopia, 2018

\begin{tabular}{|c|c|c|c|c|c|c|}
\hline \multirow[t]{3}{*}{ Variables } & & \multicolumn{2}{|c|}{ Amputation } & \multirow[t]{3}{*}{ CHR(95\% Cl) } & \multirow[t]{3}{*}{$\operatorname{AHR}(95 \% \mathrm{Cl})$} & \multirow[t]{3}{*}{$P$-value } \\
\hline & & \multirow{2}{*}{$\begin{array}{l}\text { Yes } \\
\mathrm{N}(\%)\end{array}$} & \multirow{2}{*}{$\begin{array}{l}\text { No } \\
\text { N (\%) }\end{array}$} & & & \\
\hline & & & & & & \\
\hline \multirow[t]{2}{*}{ Sex } & Male & 19 (29.69) & $45(70.31)$ & $1.46(0.67-3.52)$ & & 0.158 \\
\hline & Female & $16(31.37)$ & $35(68.63)$ & 1 & & \\
\hline \multirow[t]{6}{*}{ Age } & $18-27$ & $2(12.50)$ & $14(87.50)$ & 1 & & 0.115 \\
\hline & $28-37$ & $4(28.57)$ & $10(71.43)$ & $1.76(0.79-3.75)$ & & 0.184 \\
\hline & $38-47$ & $7(46.67)$ & $8(53.33)$ & $2.10(0.98-6.95)$ & & 0.150 \\
\hline & $48-57$ & 8 (33.33) & $16(66.67)$ & $3.24(0.69-7.74)$ & & 0.228 \\
\hline & $58-67$ & $9(34.62)$ & $17(65.38)$ & $2.76(0.89-8.56)$ & & 0.187 \\
\hline & $68-77$ & $5(25.00)$ & $15(75.00)$ & $3.61(0.94-7.76)$ & & 0.223 \\
\hline \multirow[t]{2}{*}{ Types of DM } & Type 2 DM & $23(37.70)$ & $38(62.30)$ & $1.47(0.86-6.73)$ & & 0.074 \\
\hline & Type 1 DM & $12(22.22)$ & 42 (77.78) & 1 & & \\
\hline \multirow[t]{2}{*}{ Residence } & Rural & 17 (29.82) & 40 (70.18) & $2.73(0.48-7.73)$ & & 0.247 \\
\hline & Urban & $18(31.03)$ & $40(68.97)$ & 1 & & \\
\hline \multirow[t]{2}{*}{ Co-morbidity } & Yes & $23(39.66)$ & $35(60.34)$ & $2.74(0.70-7.47)$ & & 0.190 \\
\hline & No & $12(21.05)$ & 45((78.95) & 1 & & \\
\hline \multirow[t]{2}{*}{ Wagner grades } & Grade $<4$ & $19(21.84)$ & $64(78.16)$ & 1 & 1 & $0.005^{*}$ \\
\hline & Grade $\geq 4$ & $16(57.14)$ & $16(20.00)$ & $4.70(1.96-8.63)$ & $1.59(1.49-7.48)$ & \\
\hline \multirow[t]{2}{*}{ Antibiotics given } & Appropriate & $14(36.84)$ & $24(63.16)$ & 1 & 1 & $0.017^{*}$ \\
\hline & Inappropriate & $21(53.85)$ & $18(46.15)$ & $3.48(1.84-9.53)$ & $2.14(1.64-10.63)$ & \\
\hline
\end{tabular}

"Shows statistically significant $p$-value $<0.05$ at $95 \% \mathrm{Cl}$

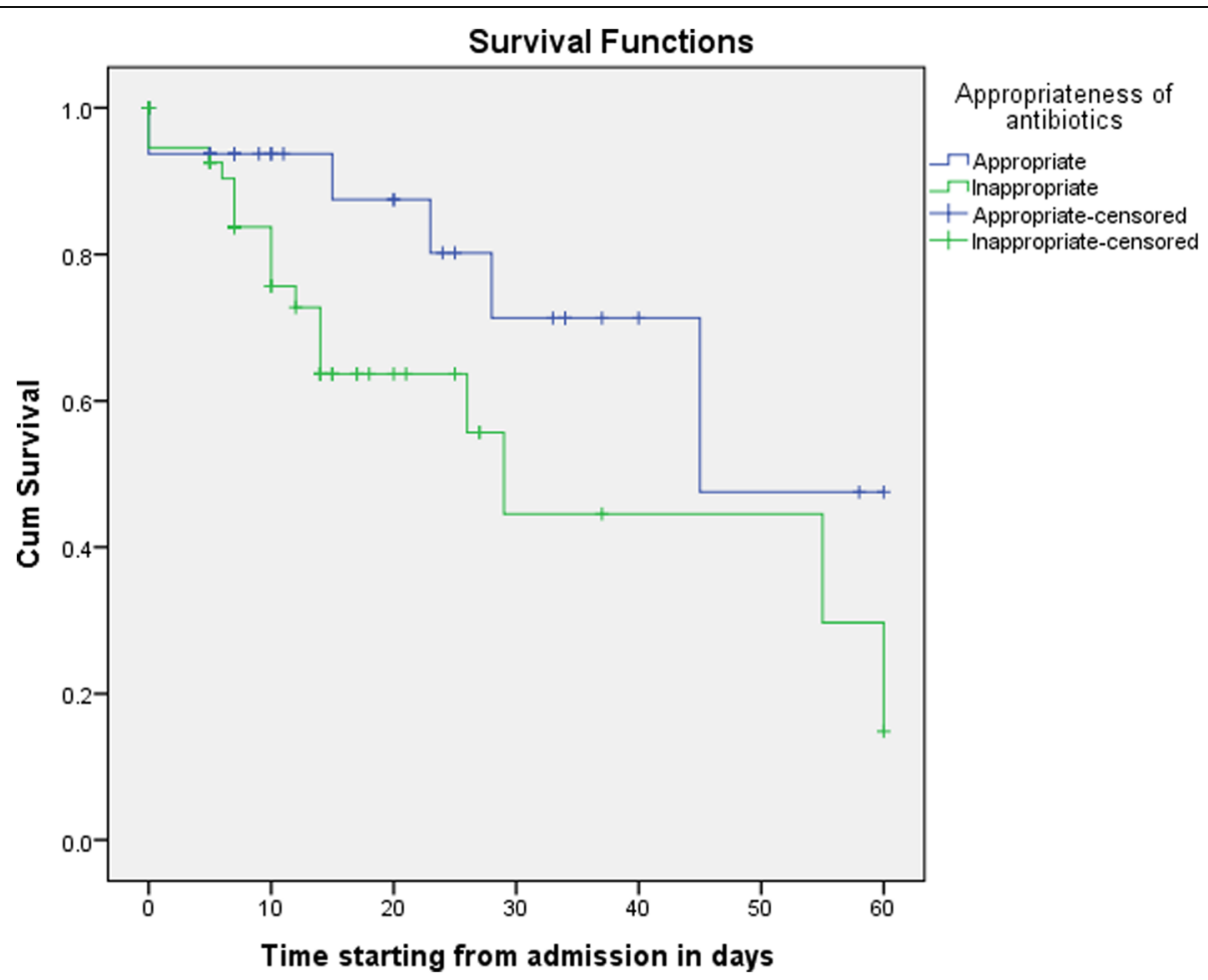

Fig. 1 Kaplan-Meier curves for amputation-free survival of diabetes foot ulcer patients over 60 days, depending on the appropriateness of antibiotics prescribed 
The Kaplan-Meier survival analyses of the patients who were on Wagner grade less than 4 and grade 4 and above showed that the healing time of diabetes foot ulcer patients who were on the advanced stage of diabetes foot ulcer was prolonged than diabetes foot ulcer patients who were at an earlier stage (Fig. 2).

\section{Discussion}

The study was aimed to identify the amputation rate of diabetes foot ulcer and its predictors. Appropriate anti-microbial therapy is essential for diabetes foot ulcers that progressed to infection, unlike this; prescribing antibiotics for uninfected foot ulcers can results in unnecessary therapy, increase cost, and risk of antibiotic resistance [17]. Therefore, appropriate use of antibiotics is a very crucial problem for clinicians. Duration of antibiotic therapy for a diabetes foot infection should be based on the severity of the infection and clinical response to therapy, and antibiotic therapy can generally be discontinued when the patients don't show any clinical presentation of infection [13]. One medical doctor, one nurse were selected as data collectors as they had experience in treatment of DFU.

The study conducted by Fatma I. Abo El-Ela et al. showed appropriate treatment of diabetes foot infection by amoxicillin and doxycycline help to prevent bacterial growth and ulcers that heal the wounds within a short period [18]. According to the study done in China by Chu et al., for moderate/severe infection, the healing rate was rapid in patients given appropriate antibiotic therapy [17]. This is similar to our study in which appropriate antibiotics prescription can fasten the healing rate of diabetes foot ulcers. This is because in China and the Nekemte referral hospital the antibiotics were started when the patients reach the advanced stage of grade. In our study, almost half of the antibiotics were prescribed inappropriately due to a lack of clinical pharmacy service that can improve the rational antibiotics prescription. Therefore, because of excessive and inappropriate use of antibiotics for treating diabetes foot infections, resistance to the usually employed bacteria wills possibly increasing to alarming levels in the study area unless tackled. The International Working Group on the Diabetic Foot Also recommends selecting antibiotic agents for treating diabetic foot infection from among those that have demonstrated efficacy for diabetic foot infection in clinical studies [19].

On the contrary, the study conducted in Denmark revealed that the antibiotics given were not significantly

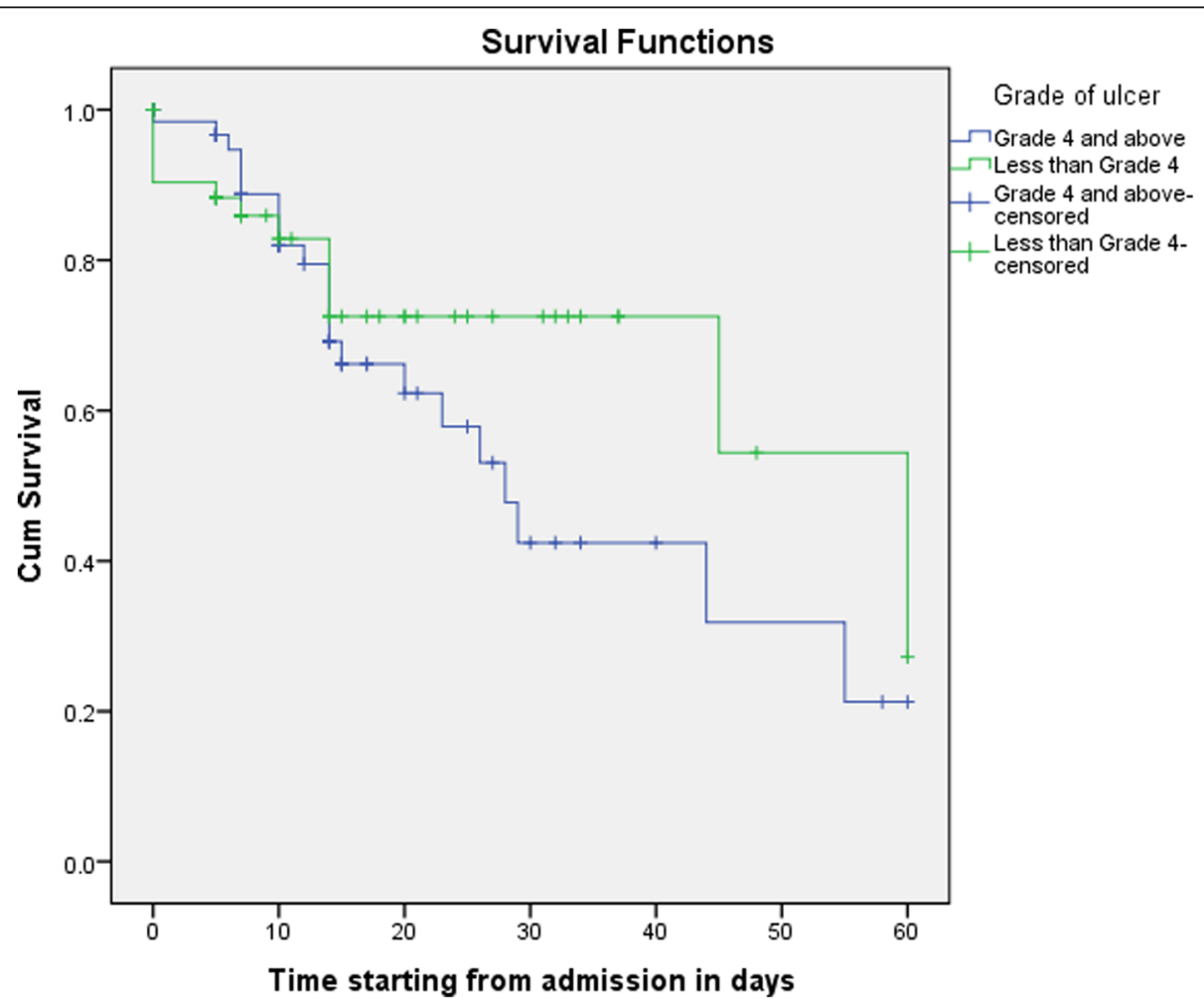

Fig. 2 Kaplan-Meier curves for amputation-free survival of diabetes foot ulcer patients over 60 days, depending on the grades of diabetic foot ulcers 
associated with the healing rate of diabetes foot ulcers [20]. This was in agreement with our study.

In our study, the rate of healing of almost half of the patients' wounds was very rapidly, i.e., greater than 2 $\mathrm{cm}^{2} /$ week. On the contrary, in Saudi Arabia the rate of healing of more than three-fourths of patients' wounds was very slow, i.e., less than $1 \mathrm{~cm} 2 /$ week [1]. The rapid healing rate of diabetes foot ulcers in our study was due to initial Wagner's grades of the majority of diabetes foot ulcer patients.

We found the average duration for ulcer healing in our study was 42 days, which was a relatively short time compared to the study of Saudi Arabia of 3 months, Denmark of about 6 months and the USA of 133 days $[10,20,21]$, and in the UK the healing rate was 2 months which was almost similar to our study [22]. The accelerated healing times might be due to the superficial infections of foot ulcer in majority of cases in our study.

The finding was not similar to those of Markuson et al., who identified a difference with in the type of diabetes and healing time. More patients in type one diabetes mellitus had rapid healing rate than type two diabetes mellitus [21]. In UK the healing rate was similar in both type one and two diabetes mellitus patients [22]. This is similar to our study in which type of diabetes couldn't affect the healing rate.

Advanced Wagner grades ( $\geq$ grade 4 ) predicted the amputation rate of diabetes foot ulcers in our study. This is because gangrene was developed at an advanced grade of foot ulcer which finally results in amputation. Similarly, Sung Hun Won, et al. showed that advanced grade of ulcer had a risk of amputation [23], similar to our study. This is due to the patients at a higher levels of Wagner's grade seek hospital after gangrene was developed in our study.

The amputation rates of foot ulcers were higher than the study done by Morbach et al. [24]. This is because all amputation levels (minor and major) were included in our study over the study period of 3 months. The study conducted in Brazil revealed that about $11.7 \%$ of the diabetic foot ulcer patients were undergone amputation [25], which was lower than our study. This may be due to a lack of quality of health service, inadequate healthcare professionals to provide care for the patients in our study. The healing rate was comparable with the study conducted by Akturk A, etal, in which $67 \%$ of the DFU were healed [26].

\section{Strength and limitation of the study}

As strength, the study was conducted among DFU patients as the foot complication of diabetes mellitus patients is increasing in the developing world and may be used as baseline information for other researchers. As limitations, culture, and sensitivity tests were not done to identify the specific strains of the pathogen. Further the follow-up period was short, thus failing to take into account any non- healing ulcers after 3 months and patients were followed by telephone not by face to face interviews. Despite the mortality was not reported in our study, further research should be conducted to identify the mortality rate. Lastly, there might be selection bias due to convenience sampling technique of the study.

\section{Conclusion}

The healing rate of diabetes foot ulcers was rapid and the majority of them were healed within 2 months. The amputation rate of diabetes foot ulcers was rapid for patients prescribed inappropriate antibiotics therapy and an advanced grade of foot ulcers. Therefore, the presence of clinical pharmacists plays a pivotal role to facilitate and promote the appropriate use of antibiotics by intervening different problems in prescribing, dispensing, and providing necessary advice for the patients, and health care professionals regarding the overall issues related to drugs. Besides the daily care, special attention should be given for patients having advanced grades of diabetes foot ulcers.

\section{Abbreviations}

AHR: Adjusted hazard ratio; BMI: Body mass index; CHR: Crude hazard ratio; Cl: Confidence interval; DFU: Diabetic foot ulcer; DM: Diabetes mellitus;

IDSA: Infectious Diseases Society of America; IWGDF: International Working Group on the Diabetic Foot; LEA: Lower extremity amputation;

$\mathrm{NRH}$ : Nekemte referral hospital; SD: Standard deviation; SPSS: Statistical package for social sciences; UK: United Kingdom

\section{Acknowledgments}

We thank Jimma University for funding this study. We are grateful to health care professionals of $\mathrm{NRH}$, data collectors, and study participants that extended their helpful hands toward the study.

\section{Authors' contributions}

FB contributes to the proposal preparation, study design, and writes up the manuscript. LC contributed to the design of the study and edition of the manuscripts. Both authors made substantial contributions to conception, acquisition of data, or analysis and interpretation of data; took part in drafting the article or revising it critically for important intellectual content; gave final approval of the version to be published; and agree to be accountable for all aspects of the work.

Funding

The study was funded by Jimma University.

\section{Availability of data and materials}

The datasets used during the study are available from the corresponding author on a reasonable request.

\section{Ethics approval and consent to participate}

Ethical clearance was obtained from the Institutional Review Board (IRB) of Jimma University, with a reference number of IHRPGC/104/208. The ethics waiver was not applicable since the study was not a randomized clinical trial so that the study subjects never have been divided into experimental and control groups. Permission was obtained from the medical director of the $\mathrm{NRH}$ to access diabetes patients and conducts the study. The benefit and risks of the study were explained to each participant included in the study and written consent were obtained from each patient involved in the study. To ensure confidentiality, name and other identifiers of patients and health care professionals were not recorded on the data collection tools. 


\section{Consent for publication}

Not applicable. No individual person's personal details, images, or videos were being used in this study.

\section{Competing interests}

No competing interests exist.

\section{Author details}

'Department of Pharmacy, College of Health Science, Mettu University, Mettu, Ethiopia. ${ }^{2}$ School of Pharmacy, College of Health Science, Addis Ababa University, Addis Ababa, Ethiopia.

Received: 8 May 2020 Accepted: 20 October 2020

Published online: 04 November 2020

\section{References}

1. Al-Menawah A-S. Determinants of diabetic foot wound healing rate. Med J Cairo Univ. 2013;81(2).

2. Musa HG, Ahmed MEM. Associated risk factors and management of chronic diabetic foot ulcers exceeding 6 months'duration. Diabet Foot Ankle. 2012; 3:18980.

3. Zhang S, Wang S, Xu L, He Y, Xiang J, Tang Z. Clinical outcomes of transmetatarsal amputation in patients with diabetic foot ulcers treated without revascularization. Diab Ther. 2019;10(4):1465-72.

4. Formosa C, Vella ML, Gatt A. Characteristics predicting foot ulceration outcomes in the diabetic foot: SMGroup; 2016. Epub July 18, 2016.

5. Gebrekirstos K, Solomon KG, Fantahun A. Prevalence and factors associated with diabetic foot ulcer among adult patients in ayder referral hospital diabetic clinic Mekelle, North Ethiopia, 2013. J Diab Metab. 2015;6(08).

6. Leung HB, Ho YC, Carnett J, Lam PK, Wong WC. Diabetic foot ulcers in the Hong Kong Chinese population: retrospective study. Hong Kong Med J. 2001;7(4):350-5.

7. Vadiveloo T, Jeffcoate W, Donnan PT, Colhoun HC, McGurnaghan S, Wild S, McCrimmon R, Leese GP, Scottish Diabetes Research Network Epidemiology Group. Amputation-free survival in 17,353 people at high risk for foot ulceration in diabetes: a national observational study. Diabetologia. 2018; 61(12):2590-7.

8. Oyibo SO, Jude EB, Tarawneh I, Nguyen HC, Armstrong DG, Harkless LB, Boulton AJ. The effects of ulcer size and site, patient's age, sex and type and duration of diabetes on the outcome of diabetic foot ulcers. Diabet Med. 2001;18(2):133-8.

9. Jeyaraman K, Berhane T, Hamilton M, Chandra AP, Falhammar H. Mortality in patients with diabetic foot ulcer: a retrospective study of 513 cases from a single Centre in the Northern Territory of Australia. BMC Endocr Disord. 2019;19(1):1

10. AlGoblan AS, Alrasheedi IM, Basheira OH, Haider KH. Prediction of diabetic foot ulcer healing in type 2 diabetic subjects using routine clinical and laboratory parameters. Res Rep Endocr Disord. 2016;6.

11. Prompers L, Schaper N, Apelqvist J, Edmonds M, Jude E, Mauricio D, Uccioli $L$, Urbancic V, Bakker K, Holstein P, Jirkovska A. Prediction of outcome in individuals with diabetic foot ulcers: focus on the differences between individuals with and without peripheral arterial disease. EURODIALE Study Diabetologia. 2008;51(5):747-55.

12. Gulam-Abbas Z, Lutale JK, Morbach S, Archibald LK. Clinical outcome of diabetes patients hospitalized with foot ulcers, Dar es Salaam, Tanzania. Diabet Med. 2002;19(7):575-9.

13. Lipsky BA, Berendt AR, Cornia PB, Pile JC, Peters EJ, Armstrong DG, Deery HG, Embil JM, Joseph WS, Karchmer AW, Pinzur MS. 2012 Infectious Diseases Society of America clinical practice guideline for the diagnosis and treatment of diabetic foot infections. Clin Infect Dis. 2012;54(12):e132-73.

14. American Diabetes Association. 10. Microvascular complications and foot care: standards of medical care in diabetes-2018. Diabetes Care. 2018; 41(Supplement 1):S105-18.

15. Wagner FW Jr. The dysvascular foot: a system for diagnosis and treatment Foot Ankle. 1981;2(2):64-122.

16. Bekele F, Fekadu G, Bekele K, Dugassa D. Incidence of diabetic foot ulcer among diabetes mellitus patients admitted to Nekemte referral Hospital, Western Ethiopia: prospective observational study. Endocrinol Metab Syndr. 2019;8(2):1-5.

17. Chu Y, Wang C, Zhang J, Wang P, Xu J, Ding M, Li X, Hou X, Feng S, Li X. Can we stop antibiotic therapy when signs and symptoms have resolved in diabetic foot infection patients? Int J Low Extrem Wounds. 2015 Sep;14(3): 277-83.

18. El-Ela Fl, Farghali AA, Mahmoud RK, Mohamed NA, Moaty SA. New approach in ulcer prevention and wound healing treatment using doxycycline and amoxicillin/LDH Nanocomposites. Sci Rep. 2019;9(1):1-5.

19. Lipsky BA, Senneville É, Abbas ZG, Aragón-Sánchez J, Diggle M, Embil JM, Kono S, Lavery LA, Malone M, van Asten SA, Urbančič-Rovan V. Guidelines on the diagnosis and treatment of foot infection in persons with diabetes (IWGDF 2019 update). Diabetes Metab Res Rev. 2020;36:e3280.

20. Buhl Sørensen ML, Jansen RB, Fabricius TW, Jørgensen B, Svendsen OL. Healing of diabetic foot ulcers in patients treated at the Copenhagen wound healing center in 1999/2000 and in 2011/2012. J Diab Res. 2019;2019:9.

21. Markuson M, Hanson D, Anderson J, Langemo D, Hunter S, Thompson P, Paulson R, Rustvang D. The relationship between hemoglobin A1C values and healing time for lower extremity ulcers in individuals with diabetes. Adv Skin Wound Care. 2009;22(8):365-72.

22. Robertshaw $L$, Robertshaw DA, Whyte I. Audit of time taken to heal diabetic foot ulcers. Pract Diab Int. 2001;18(1):6-9.

23. Won SH, Chung CY, Park MS, Lee T, Sung KH, Lee SY, Kim TG, Lee KM. Risk factors associated with amputation-free survival in patient with diabetic foot ulcers. Yonsei Med J. 2014;55(5):1373-8.

24. Morbach S, Furchert H, Gröblinghoff U, Hoffmeier H, Kersten K, Klauke GT, Klemp U, Roden T, Icks A, Haastert B, Rümenapf G. Long-term prognosis of diabetic foot patients and their limbs: amputation and death over the course of a decade. Diabetes Care. 2012;35(10):2021-7.

25. Dutra LM, Melo MC, Moura MC, Leme LA, De Carvalho MR, Mascarenhas AN, Novaes MR. Prognosis of the outcome of severe diabetic foot ulcers with multidisciplinary care. J Multidiscip Healthc. 2019;12:349.

26. Akturk A, Van Netten JJ, Scheer R, Vermeer M, van Baal JG. Ulcer-free survival days and ulcer healing in patients with diabetic foot ulcers: A prospective cohort study. Int Wound J. 2019;16(6) https://doi.org/10.1111/ iwj.13199.

\section{Publisher's Note}

Springer Nature remains neutral with regard to jurisdictional claims in published maps and institutional affiliations.

Ready to submit your research? Choose BMC and benefit from:

- fast, convenient online submission

- thorough peer review by experienced researchers in your field

- rapid publication on acceptance

- support for research data, including large and complex data types

- gold Open Access which fosters wider collaboration and increased citations

- maximum visibility for your research: over $100 \mathrm{M}$ website views per year

At $\mathrm{BMC}$, research is always in progress.

Learn more biomedcentral.com/submissions 